\title{
Iñvestigating Effectiveness of Happiness Training on Psychological Well-Being and Optimism of Pregnant Women with a History of Spousal Abuse
}

\author{
Mozhgan Abdos ${ }^{1}$, Mojtaba Aghili², Akram Sanagoo*3, Ali Kavosi ${ }^{3}$ \\ 1- Islamic Azad University of Goroan, Gorgan, Iran \\ 2- $\quad$ Payam Noor University of Gorgan, Gorgan, Iran \\ 3- $\quad$ Nursing Research Center, Goletsan University of Medical Sciences, Gorgan Iran
}

\begin{abstract}
Background and objectives: Spousal abuse, also known as domestic violence, can impose negative psychological effects on women, including a decline in psychological well-being and optimism. Hence, development of capabilities such as happiness can be helpful in coping with these outcomes. Therefore, the purpose of this study was to investigate the effectiveness of happiness training on the psychological well-being and optimism of pregnant women with a history of spousal abuse.

Methods: In this semi-experimental study (with a pretest and posttest design), 30 pregnant women who were referred to health centers of Gorgan (Iran) in 2015 were selected via non-random sampling. The subjects were randomly divided into an experimental group $(n=15)$ and a control group $(\mathrm{n}=15)$. The experimental group received 10 sessions of happiness training, but the control group received no training. Data were collected using a demographic questionnaire, the Ryff's psychological well-being scale and an optimism questionnaire. Data analysis was done using the SPSS software (version 16) and descriptive and inferential statistics at significance level of 0.05.

Results: The happiness training significantly increased the level of psychological well-being and optimism. There was a significant difference in the mean score of psychological well-being and optimism between the two groups $(\mathrm{P}$-value $=0.001)$

Conclusion: The findings show that happiness training significantly improves happiness and psychological well-being in women with a history of domestic violence. We recommend performing future studies with a larger study population and short- and long-term follow-ups to evaluate the effectiveness of such training over time.
\end{abstract}

KEYWORDS: Education, Happiness, Psychological well-being, Optimism, Pregnant women, Spousal abuse

Received: 2018/11/15

Revised: 2018/12/01

Published:2019/01/12

*Correspondence: Dr Akram Sanagoo

Address: Nursing Research Center, Goletsan University of Medical Sciences, Gorgan Iran

Telephone: +98-9112703978 Email: sanagoo@goums.ac.ir 


\section{INTRODUCTION}

Today, the issue of violence against women is known as an important social problem. Spousal abuse, also known as domestic violence, is one of the most prominent cases of human rights violation. This serious issue is common in many cultures and has permanent and destructive effects on various aspects of a woman's live (1). Pregnant women are higher risk of being confronted with domestic violence. Pregnancy increases the incidence of domestic violence for various reasons, including reduced frequency of intercourse, misconceptions about pregnancy and abnormal attitude of spouse towards pregnancy (2). The prevalence of spousal abuse during pregnancy is reported to be between $9 \%$ and $21 \%$ (3). Continuous domestic violence not only affects the pregnancy outcome (such as low weight at birth and premature birth), but also significantly affects the mental health and well-being of parents (4). The psychological consequences of spousal abuse during pregnancy include depression, mood disorder, anxiety disorder, somatization disorder and feeling of inadequacy (5).

Psychological well-being is defined as a positive assessment of life and balance between positive and negative affect (6). Various factors such as inner satisfaction, history of abortion, gestational age, intended/unintended pregnancy, social communications, life events and personality traits can influence the psychological wellbeing of pregnant women (7). Cognitive behavioral therapies, including happiness training, can be effective in making positive changes to life problems and increasing happiness and psychological well-being (8). Happiness is defined as having positive or pleasant emotions and feelings towards oneself. This assessment includes emotional reactions to events and cognitive judgments about life satisfaction and accomplishments (9). Happiness can be effective in preventing mental disorders in victims of domestic violence, and help them cope better with the violence and reduce maltreatment in marital relationships (10). Studies show that positive personality traits can positively influence the psychological well-being of pregnant women. Optimism is one of the cognitive constructs that lead to happiness and well-being (11). In fact, optimistic people generally experience more positive outcomes because they imagine their goal to be achievable and use more problem-solving processes (12). They are more satisfied with their lives and feel healthier and happier than other people (13). In recent years, much attention has been paid to the mental health of pregnant women and its subsequent effect on the physical and mental health of fetus. Studies have sought to identify sources of stress and tension in pregnant women in order to provide suitable solutions for increasing satisfaction and happiness in these individuals (14). Considering the importance of pregnancy and the effect of this period on the health of mother and child, this study examined effect of happiness training on the psychological well-being and optimism of pregnant women with a history of spousal abuse.

\section{MATERIAL AND METHODS Study design and population}

In this semi-experimental study (with a pretest and posttest design), all pregnant women who were referred to the health centers of Gorgan (Iran) in 2015 were enrolled. Overall, 30 pregnant women were selected via non-random sampling. The subjects were randomly divided into an experimental group $(n=15)$ and a control group $(n=15)$. It should be noted that the two groups were matched in terms of demographic characteristics.

\section{Inclusion/exclusion criteria}

Pregnant women (second trimester) aged 2040 years with/without history of domestic violence who were literate, willing to participate in the study and residing in Gorgan were included in the study. Drug addiction and history of illness, high-risk pregnancy, referral to a psychiatrist, drug use or hospitalization due to mental illness over the past year and severe tension in the past six 
months (mourning or divorce) were the exclusion criteria.

\section{Data collection tools}

Data were collected using a demographic questionnaire, the Ryff's psychological wellbeing scale and an optimism questionnaire.

The demographic questionnaire included questions about age, education and employment of the subjects. The Ryff's psychological well-being scale was used for evaluation of psychological well-being (scored 18 to 126) (15). Validity, reliability and internal consistency of this questionnaire have been confirmed $(16,17)$. Optimism was measured using the questionnaire designed by Carver and Scheier (scored 0 to 24) (18). Validity and reliability of this questionnaire have been verified previously $(19,20)$.

The Ryff's psychological well-being scale consists of 18 items with six factors: selfacceptance, positive relations with others positive, autonomy, purpose in life, personal growth and environmental mastery (15). The participants' response was scored based on a 7-point Likert scale: strongly disagree (score 1); disagree (score 2); somewhat disagree (score 3); neither agree nor disagree (score 4); somewhat agree (score 5); agree (score 6); strongly agree (score 7). A higher score indicates a higher level of psychological wellbeing in pregnant women.

The optimism questionnaire designed by Carver and Scheier consists of 10 items, of which four items are divertive (18). The responses were scored based on the Likert scale: strongly agree (score 4); agree (score 3 ); no comment (score 2); strongly disagree (score 1).

\section{Fordyce happiness intervention program}

Happiness training sessions (120 minutes a session) based on the Fordyce model was held twice a week for five weeks, with help of a doctor of psychology (Table 1). The training was provided only to subjects in the experimental group.

Table 1. Summary of the Fordyce happiness cognitive-behavioral training

\begin{tabular}{|c|c|c|}
\hline Session & Topic & Brief description \\
\hline 1 & Introductory meeting-pretest & $\begin{array}{l}\text { 1. Introductions } \\
\text { 2. Instructions } \\
\text { 3. Handing out the psychological well-being and } \\
\text { optimism questionnaires }\end{array}$ \\
\hline 2 & $\begin{array}{l}\text { Formula of happiness, increased } \\
\text { happiness with physical activity }\end{array}$ & $\begin{array}{l}\text { 1. Introducing the happiness formula } \\
\text { 2. Overview of happiness techniques } \\
\text { 3. Providing a technique for increasing physical activity }\end{array}$ \\
\hline 3 & $\begin{array}{l}\text { Increase in happiness with social } \\
\text { skills }\end{array}$ & $\begin{array}{l}\text { 1. Presenting formula of happiness } \\
\text { 2. Providing techniques for improving social } \\
\text { relationships }\end{array}$ \\
\hline 4 & Optimism and its effects & Providing a technique for increased optimism \\
\hline 5 & Creativity and its effects & Providing a technique for developing creativity \\
\hline 6 & $\begin{array}{l}\text { How to escape anxiety, reduce } \\
\text { expectations and express feelings }\end{array}$ & $\begin{array}{l}\text { 1. Providing a technique for escaping anxiety } \\
\text { 2. Providing a technique for reducing expectations }\end{array}$ \\
\hline 7 & Increased intimacy and being oneself & Providing the appropriate technique \\
\hline 8 & Focus on the present & Providing the appropriate technique \\
\hline 9 & Planning training & Providing the appropriate technique \\
\hline 10 & Review-posttest & $\begin{array}{l}\text { 1. Providing a technique for prioritizing happiness } \\
\text { 2. Reviewing the } 10 \text { joyful techniques explained in } \\
\text { previous sessions } \\
\text { 3. Handing out the questionnaires in posttest }\end{array}$ \\
\hline
\end{tabular}




\section{Statistical analysis}

Data collected from the completed questionnaires were analyzed with SPSS software (version 16). Descriptive statistics (frequency, mean and standard deviation) and inferential statistics (one-way ANCOVA, Fisher's exact test, t-test and paired t-test) were used for data analysis. All analyses were performed at significance of 0.05 .

\section{Ethical considerations}

Before obtaining written consent from all participants, the researchers explained the purpose of the research to participants and ensured anonymity and confidentiality of data. It should be noted that the training program was also offered to pregnant women in the control group after the study.

\section{RESULTS}

The mean age of pregnant women was $28.8 \pm$ 4.34 years in the experimental group and 28.4 \pm 5.09 years in the control group (Table 2 ).

Table 2. Absolute and relative frequency distribution of demographic characteristics of pregnant women in the study groups

\begin{tabular}{|c|c|c|c|c|c|c|}
\hline \multirow{2}{*}{\multicolumn{2}{|c|}{ Demographic information }} & \multicolumn{2}{|c|}{ Control group } & \multicolumn{2}{|c|}{ Experimental group } & \multirow{3}{*}{$\begin{array}{c}\text { Statistical test } \\
\text { Chi-square } \\
\text { and Fisher's } \\
\text { exact test }\end{array}$} \\
\hline & & \multirow{3}{*}{$\begin{array}{c}\text { Percent } \\
26.6\end{array}$} & \multirow{3}{*}{$\begin{array}{c}\text { Number } \\
4\end{array}$} & \multirow{3}{*}{$\begin{array}{c}\text { Percent } \\
26.6\end{array}$} & \multirow{3}{*}{$\begin{array}{c}\text { Number } \\
4\end{array}$} & \\
\hline \multirow{5}{*}{ Age } & & & & & & \\
\hline & $20-20$ & & & & & \multirow{4}{*}{$\mathrm{F}=0.091$} \\
\hline & $27-33$ & 60 & 9 & 53.4 & 8 & \\
\hline & $34-40$ & 13.4 & 2 & 20 & 3 & \\
\hline & Total & 100 & 15 & 100 & 15 & \\
\hline \multirow{4}{*}{$\begin{array}{c}\text { Education } \\
\text { level }\end{array}$} & $\begin{array}{l}\text { Illiterate/under } \\
\text { high school } \\
\text { diploma } \\
\end{array}$ & 20 & 3 & 26.6 & 4 & \multirow{4}{*}{$\mathrm{F}=0.811$} \\
\hline & $\begin{array}{l}\text { High school } \\
\text { diploma }\end{array}$ & 40 & 6 & 33.4 & 5 & \\
\hline & $\begin{array}{c}\text { University } \\
\text { degree }\end{array}$ & 40 & 6 & 40 & 6 & \\
\hline & Total & 100 & 15 & 100 & 15 & \\
\hline \multirow{3}{*}{$\begin{array}{l}\text { Employment } \\
\text { status }\end{array}$} & Employed & 20 & 3 & 26.6 & 4 & \multirow{3}{*}{$X^{2}=0.827$} \\
\hline & Housewife & 80 & 12 & 73.4 & 11 & \\
\hline & Total & 100 & 15 & 100 & 15 & \\
\hline
\end{tabular}

According to the results presented in tables 3 and 4, the happiness training increased the components of psychological well-being and optimism in pregnant women with a history of spousal abuse.

Table 3. Mean pretest and posttest scores of psychological well-being in the study groups

\begin{tabular}{|c|c|c|c|c|c|c|c|c|c|}
\hline \multirow[t]{3}{*}{ Subscales } & \multicolumn{4}{|c|}{ Control group } & \multicolumn{4}{|c|}{ Experimental group } & \multirow{3}{*}{ T-Test } \\
\hline & \multicolumn{2}{|c|}{ Posttest } & \multicolumn{2}{|c|}{ Pretest } & \multicolumn{2}{|c|}{ Posttest } & \multicolumn{2}{|c|}{ Pretest } & \\
\hline & SD & Mean & SD & Mean & SD & Mean & SD & Mean & \\
\hline
\end{tabular}


Journal of Clinical and Basic Research (JCBR): 2018: Vol 2: N4.P: 33-40

\begin{tabular}{|c|c|c|c|c|c|c|c|c|c|}
\hline Life satisfaction & 2.16 & 7.33 & 2.24 & 6.2 & 1.94 & 13.27 & 2.69 & 8.67 & \\
\hline Paired t-test & \multicolumn{4}{|c|}{$\mathrm{P}=0.092$} & \multicolumn{4}{|c|}{$\mathrm{P}=0.001$} & $\mathrm{P}=0.001$ \\
\hline Spirituality & 2.78 & 7.07 & 2.44 & 6.4 & 2.05 & 15.67 & 3.39 & 11.37 & \multirow[b]{2}{*}{$\mathrm{P}=0.045$} \\
\hline Paired t-test & \multicolumn{4}{|c|}{$\mathrm{P}=0.263$} & \multicolumn{4}{|c|}{$\mathrm{P}=0.011$} & \\
\hline Happiness & 2.96 & 6.67 & 3.05 & 6.8 & 1.92 & 14 & 2.23 & 6.13 & \multirow{2}{*}{$\mathrm{P}=0.001$} \\
\hline Paired t-test & \multicolumn{4}{|c|}{$\mathrm{P}=0.892$} & \multicolumn{4}{|c|}{$\mathrm{P}=0.001$} & \\
\hline Personal growth & 2.47 & 6.53 & 2.99 & 7.4 & 1.38 & 11.93 & 2.19 & 11.6 & \multirow[b]{2}{*}{$\mathrm{P}=0.196$} \\
\hline Paired t-test & \multicolumn{4}{|c|}{$\mathrm{P}=0.154$} & \multicolumn{4}{|c|}{$\mathrm{P}=0.736$} & \\
\hline Self-acceptance & 2.29 & 6 & 3.04 & 6.4 & 0.83 & 12.47 & 2.16 & 11.13 & \multirow{2}{*}{$\mathrm{P}=0.001$} \\
\hline Paired t-test & \multicolumn{4}{|c|}{$\mathrm{P}=0.813$} & \multicolumn{4}{|c|}{$\mathrm{P}=0.091$} & \\
\hline Positive relations & 2.57 & 6.93 & 2.23 & 6.13 & 0.88 & 11.93 & 2.53 & 10.87 & \multirow[b]{2}{*}{$\mathrm{P}=0.092$} \\
\hline Paired t-test & \multicolumn{4}{|c|}{$\mathrm{P}=0.113$} & \multicolumn{4}{|c|}{$\mathrm{P}=0.041$} & \\
\hline $\begin{array}{c}\text { Total score of } \\
\text { psychological well- } \\
\text { being }\end{array}$ & 6.41 & 40.53 & 9.74 & 39.33 & 5.47 & 79.27 & 6.17 & 60.13 & \multirow{2}{*}{$\mathrm{P}=0.001$} \\
\hline Paired t-test & \multicolumn{4}{|c|}{$P=0.642$} & \multicolumn{4}{|c|}{$\mathrm{P}=0.001$} & \\
\hline
\end{tabular}

Table 4. Mean pretest and posttest scores of optimism in the study groups

\begin{tabular}{|c|c|c|c|c|c|c|c|c|c|}
\hline \multirow{3}{*}{ Subscale } & \multicolumn{4}{|c|}{ Control group } & \multicolumn{3}{c|}{ Experimental group } & \multirow{2}{*}{ T-Test } \\
\cline { 2 - 10 } & \multicolumn{2}{|c|}{ Posttest } & Pretest & \multicolumn{2}{c|}{ Posttest } & \multicolumn{2}{c|}{ Pretest } & \\
\cline { 2 - 9 } & SD & Mean & SD & Mean & SD & Mean & SD & Mean & \\
\hline Optimism & 7.84 & 18.07 & 5.03 & 16.93 & 2.58 & 31.87 & 4.75 & 18.73 & \multirow{2}{*}{$\mathrm{P}=0.001$} \\
\hline Paired t-test & \multicolumn{4}{|c|}{$\mathrm{P}=0.173$} & \multicolumn{3}{c|}{$\mathrm{P}=0.001$} & & \\
\hline
\end{tabular}

Furthermore, one-way ANCOVA showed that after eliminating the effects of pretest, there was a significant difference in the mean score of psychological well-being and optimism between the two groups $(\mathrm{P}$-value $=0.001)$. 


\section{DISCUSSION}

The results showed that the happiness training increased the components of psychological well-being, which is consistent with findings of previous studies (21-26). Generally, all humans seek happiness, which is a crucial part of life (27), but experiencing stress significantly reduces happiness, thus leading to a decline in mental health (28). Happiness training for women with a history of spousal abuse can reduce physical complaints, depression, anxiety and aggression while improving social relationships, adaptability and self-esteem. In this way, domestic violence could be avoided by accepting the problems and constraints in life and finding better solutions, which ultimately will increase the psychological well-being of these women (29).

Happiness training also increased optimism in pregnant women with a history of spousal abuse. This finding is consistent with findings of some previous studies (30-32). One of the key elements of teaching happiness is to create a model of constructive and resilience thinking, understand self-worth and avoid self-destructive behaviors when confronting problems. Moreover, promoting optimism can increase the psychological well-being of people (33). In the present study, the happiness training significantly increased optimism and subsequently psychological well-being in the subjects. This is consistent with findings of a similar study (34). Optimism can make people believe in their personal abilities and draw positive inferences from the society and environment, and thus expect positive outcomes. A positive emotional state can improve psychological and physical well-being, which will also strengthen the individual's capacity to cope with unfortunate conditions.

\section{CONCLUSION}

The findings show that happiness training significantly improves happiness and psychological well-being in women with a history of domestic violence. We recommend performing future studies with a larger study population and short- and long-term follow-
Ups to evaluate the effectiveness of this training over time.

\section{ACKNOWLEDGEMENTS}

This study was derived from a thesis for completion of a Master's degree in general psychology at the Islamic Azad University of Gorgan. The researchers would like to express their gratitude to the Deputy of Research and Technology of the Islamic Azad University of Gorgan for the financial and spiritual support.

\section{DECLARATIONS}

\section{Funding}

This study received financial support from the Islamic Azad University of Gorgan, Iran (code: 2451/55).

\section{Ethics approvals and consent to participate}

Written informed consent was obtained from all participants.

\section{Conflict of interest}

The authors declare that there is no conflict of interest.

\section{REFERENCES}

1. Soleimani M, Jamshidimanesh M, Daneshkojuri M, Hoseini F. Correlation between partner violence and preterm labor. Article in Persian] JQUMS. 2012;15(4):53-9.

2. Levendosky AA, Bogat GA, Huth-Bocks AC, Rosenblum K, von Eye A. The effects of domestic violence on the stability of attachment from infancy to preschool. Journal of Clinical Child \& Adolescent Psychology. 2011;40(3):398-410. [DOI:10.1080/15374416.2011.563460]

3. Fogarty CT, Fredman L, Heeren TC, Liebschutz J. Synergistic effects of child abuse and intimate partner violence on depressive symptoms in women. Preventive medicine. 2008;46(5):463-9.

[DOI:10.1016/j.ypmed.2007.12.009]

4. Bazmi S, Kiani M, Rezvani S, Bazmi E, Naeeji $\mathrm{H}$. Wife abuse and related factors in referred to forensic medical examination subunits of tehran legal medicine organization. Medical law. 2012. 
5. Rodrigues T, Rocha L, Barros H. Physical abuse during pregnancy and preterm delivery. American Journal of Obstetrics and Gynecology. 2008;198(2):171. e1-. e6.

6. Molavi $\mathrm{H}$, Torkan $\mathrm{H}$, Soltani I, Palahang $\mathrm{H}$. Structure standardization, validity and reliability of subjective well-being questionnaire. Iranian Journal of Psychiatry and Clinical Psychology. 2010;16(3):231-8.

7. Van den Bergh BR. Some societal and historical scientific considerations regarding the mother-fetus relationship and parenthood. Infant and Child Development. 2010;19(1):39-44. [DOI:10.1002/icd.652]

8. Mohammadi ZD, Bosaknejad S, Sarvghad S. A survey on the effectiveness of stress management training with cognitive-behavioral group therapy approach on state/trait anxiety, pregnancy anxiety and mental health of primiparous women. Jentashapir Journal of Health Research. 2013;3(4):495-504.

9. Noei-iran L, Mahmoud-Alilou M. Predicting quality of life and happiness based on attachment style. iRAnian Journal of Rehabiliation Research in Nursing. 2015;1(4):60-9.

10. Goodman L, Dutton MA, Vankos N, Weinfurt $\mathrm{K}$. Women's resources and use of strategies as risk and protective factors for reabuse over time. Violence Against Women. 2005;11(3):311-36. [DOI:10.1177/1077801204273297]

11. Carver CS, Scheier MF, Segerstrom SC. Optimism. Clinical psychology review. 2010;30(7):879-89.

[DOI:10.1016/j.cpr.2010.01.006]

12. Heene EL, Buysse A, Oost P. Indirect pathways between depressive symptoms and marital distress: The role of conflict communication, attributions, and attachment style. Family process. 2005;44(4):413-40. [DOI:10.1111/j.1545-5300.2005.00070.x]

13. Poursardar N, Poursardar F, Panahandeh A, Sangari A, ABDI ZS. Effect of Optimism on Mental Health and Life Satisfaction: A Psychological Model of Well-being. Hakim Research Journal. 2013;16(1):42-9.
14. Karami K, Mardani A. Relationship between Mental Health and Quality of Life in Pregnant Women. journal of Health Breeze. 2014;2(1):107.

15. Ryff CD. Happiness is everything, or is it? Explorations on the meaning of psychological well-being. Journal of personality and social psychology. [DOI:10.1037/0022-3514.57.6.1069]

16. Bayani AA, Mohammad Koochekya A, Bayani A. Reliability and validity of Ryff's psychological well-being scales. Iranian journal of psychiatry and clinical psychology. 2008;14(2):146-51.

17. Souri H, Hejazi E. The Relationship between Resilience and Psychological Well-being: The Mediating Role of Optimism. Health Psychology. 2014;15(55):5-15.

18. Scheier MF, Carver CS. Optimism, coping, and health: assessment and implications of generalized outcome expectancies. Health psychology. 1985;4(3):219. [DOI:10.1037/02786133.4.3.219]

19. Khodabakhshi M. Validity and reliability of optimism in Isfahan City: Dissertation for the degree of Master of General Psychology. University Isfahan; 2004.

20. Mousavinasab S, Taghavi SMR, Mohammadi N. Optimism and stress appraisal: Evaluation of two theoretical models in prediction of psychological adjustment. Journal of Kerman University of Medical Sciences. 2006;13(2):11120.

21. Fava GA, Ruini C. Increasing Psychological Well-being in Clinical and Educational Settings: Interventions and Cultural Contexts: Springer; 2014. [DOI:10.1007/978-94-017-8669-0]

22. Flora C. The pursuit of happiness. Psychology today. 2009;61:427-34.

23. Smith T. Finding happiness in a Harvard Classroom. Psychological Medicine. 2006;28:475-80.

24. Kajbaf M, Aghaei A, Mahmoody E. The Effect of Happiness Training on Couples' Life Quality in Counseling Centers in Esfahan. J Fam Res. 2011;7:69-81. 
25. Kamkary K, Shokrzadeh S. Investigate relations between mental health and happiness feel in Tehran youth people. Euro J Exp Bio. 2012;2(5):1880-6.

26. Aghili M, Mohamadi N, Ghorbani L. Evaluating the relationship between happiness and mental health in iranian athletes. J Basic Appl Sci Res. 2012;2(3):2494-7.

27. King LA, Napa CK. What makes a life good? Journal of personality and social psychology. 1998;75(1):156.

[DOI:10.1037/0022-

3514.75.1.156]

28. Jayasvasti K, Kanchanatawan B. Happiness and related factors in pregnant women. Journal of the Medical Association of Thailand= Chotmaihet thangphaet. 2005;88:S220-5.

29. Sadeghi N, Azizi S, Mollaeinezhad M. Anxiety status in pregnant mothers at third trimester of pregnancy and its related factors in referrals to Bandar Abbas Hospitals in 2012. IJOGI. 2014;17(122):8-15.

30. Pak AV, Khaledi S, Manesh KM. Efficacy of Mindfulness Training on Enhancing Optimism in Women with Pregnancy Diabetes. Health Psychology. 2015;14(14):62-78.

31. Argyle M. The psychology of happiness: Routledge; 2013. [DOI:10.4324/9781315812212]

32. Marani MR, Ahadi H, Asgari P, Bakhtyarpour S. Effectiveness of Fordyce Happiness Training on Female Students' Coping Strategies, Quality of Life and Optimism. Journal of Women and Society. 2015;6(3):25-40.

33. Strassle CG, McKee EA, Plant DD. Optimism as an indicator of psychological health: Using psychological assessment wisely. Journal of personality assessment. 1999;72(2):190-9. [DOI:10.1207/S15327752JP720203]

34. Sharifi K, Saeidi H. Prediction of psychological well-being based on the orientation of life and optimism. journal of rooyesh-eravanshenesi. 2015;4(10):41-58. 